\title{
Médiévales
}

Langues, Textes, Histoire

66 | printemps 2014

Harmonie Disharmonie

\section{Valérie TOUREILLE, Crime et châtiment au Moyen Âge} $\left(V^{e}-X V^{e}\right.$ siècle)

Paris, Seuil, 2013 (« L’Univers historique »), 329 p.

Isabelle Mathieu

\section{(2) OpenEdition}

1 Journals

Édition électronique

URL : https://journals.openedition.org/medievales/7310

DOI : 10.4000/medievales.7310

ISSN : 1777-5892

Éditeur

Presses universitaires de Vincennes

Édition imprimée

Date de publication : 30 juin 2014

Pagination : 217-218

ISBN : 978-2-84292-405-8

ISSN : 0751-2708

Référence électronique

Isabelle Mathieu, «Valérie tourelıle, Crime et châtiment au Moyen Âge ( $v^{e}-x v^{e}$ siècle) 》, Médiévales [En ligne], 66 | printemps 2014, mis en ligne le 10 juillet 2014, consulté le 22 avril 2022. URL : http:// journals.openedition.org/medievales/7310; DOI : https://doi.org/10.4000/medievales.7310

Ce document a été généré automatiquement le 22 avril 2022

Tous droits réservés 


\title{
Valérie TOUREILLE, Crime et châtiment au Moyen Âge ( $V^{e}-X V^{e}$ siècle)
}

Paris, Seuil, 2013 (« L'Univers historique »), 329 p.

\author{
Isabelle Mathieu
}

\section{RÉFÉRENCE}

Valérie TOUREILLE, Crime et châtiment au Moyen Âge ( $V^{e}-X V^{e}$ siècle), Paris, Seuil (« L'Univers historique »), 2013, $329 \mathrm{p}$.

1 V. Toureille, Maître de conférences en histoire du Moyen Âge à l'Université de CergyPontoise, propose dans cet ouvrage une belle synthèse sur le sujet impliqué par son titre. Ce dernier se présente sous la forme de quatre chapitres thématiques: le premier est consacré à la société médiévale et au crime, le second, tout en traitant des figures du crime, s'interroge sur la faisabilité de dresser "l'ébauche d'une sociologie criminelle", le troisième s'intéresse au criminel devant ses juges et, pour finir, le dernier aborde la question du traitement du crime, à savoir la punition et le pardon. Ces quatre chapitres sont divisés à leur tour en sous-chapitres (entre 3 et 5 selon les parties), ce qui rend facile à suivre le fil conducteur de la pensée de l'auteure. Si cette dernière a fait le choix du plan thématique, elle n'en oublie pas pour autant la dimension chronologique, laquelle est bien mise en avant au fil de la démonstration. L'ensemble est accompagné en fin de volume d'une bibliographie indicative. Classée thématiquement, elle fait une place aux publications récentes et aux sources éditées. En revanche, de l'aveu de l'auteure, les sources manuscrites ont été volontairement écartées car trop nombreuses. Les notes de bas de pages permettent, quant à elles, de faire des renvois précis aux sources et à la bibliographie ou d'approfondir judicieusement certains points. Bien construit, l'ouvrage est clair et sa lecture agréable. Sur la forme comme sur le fond ce travail est précis et soigné. À travers des exemples choisis insérés au fil de la plume ou isolés sous forme de petits paragraphes, on perçoit toute la richesse des normes juridiques et des archives de la pratique judiciaire: des 
juges au travail aux récits croustillants d'affaires criminelles, c'est tout l'univers judiciaire qui se donne à voir.

2 L'introduction générale du livre pose bien les objectifs que s'est assignés l'auteure: mettre à bas un certain nombre de clichés sur le Moyen Âge et a fortiori sur le fonctionnement et l'organisation de la justice, la place et la réception du crime et des châtiments dans la société médiévale; proposer un bilan historiographique en montrant quelles sont les tendances actuelles de la recherche; faire un point méthodologique sur les sources dont dispose l'historien en rappelant leurs limites et les précautions à prendre pour les exploiter efficacement ; rappeler que l'analyse d'un tel sujet ne peut pas faire l'économie de la pluridisciplinarité, notamment en intégrant les travaux et les raisonnements des historiens du droit. La dimension historiographique et méthodologique du sujet est présente tout au long de l'ouvrage, l'auteure veillant à inscrire ses propos dans une démarche historique minutieuse et nuancée. Les quatre chapitres s'ouvrent à chaque fois par une courte introduction posant le problème à traiter : par exemple, comment dire le crime? (chap. 1) ; y a-t-il un profil criminel ? (chap. 2) ; comment s'organise la répression des crimes? (chap.3); quels sont les enjeux de la répression des faits criminels? (chap. 4)

En proposant de "faire l'archéologie du vocabulaire», V. Toureille montre bien la difficulté qu'il y a à définir le terme de «crime» et, ensuite, celle d'établir une typologie précise des "crimes et délits». En effet, elle rappelle qu'il existe une multitude de façons de dire et d'écrire le crime de sorte que l'appréhender revient en fait à s'intéresser à tous ces actes qui heurtent les consciences collectives, les valeurs partagées ou la morale, et mettent en danger l'ordre social. Le crime est donc un acte qui, par définition, évolue avec les changements touchant la société et les rapports entre les hommes et les femmes. Du reste, comme l'atteste la documentation, la société médiévale est, comparée à la nôtre, une société qui entretient une plus grande proximité avec la violence et les armes - et, in fine, parfois, avec la mort -, ce qui a des conséquences sur la manière de concevoir et d'envisager le fait criminel. Ainsi, comme le souligne V. Toureille, l'assassinat que l'on considère de nos jours comme un crime grave, voire le plus répugnant, n'appelle pas toujours la réprobation des hommes et des femmes au Moyen Âge. Cela est d'autant plus vrai lorsque celui-ci est lié à une question d'honneur et de fama; ce dernier peut même, de ce fait, être complètement excusable. À l'époque médiévale, les affaires de crimes de sang sont instruites par les mêmes instances que celles qui s'occupent de traiter le reste du contentieux. L'auteure insiste bien sur le fait que «le procès criminel trouve tardivement son autonomie ». En effet, pendant longtemps, «il n'est qu'un procès civil comme un autre, divisant deux parties, susceptible d'être réglé, comme un procès civil, sur le terrain du préjudice et de la réparation. Il faut plusieurs siècles pour admettre que l'État est légitime à se substituer à la partie appelante et à juger au nom de principes supérieurs ".

4 Concernant le profil type du criminel, l'auteure montre qu'il est à chercher du côté des jeunes, dont la place est prépondérante au moins dans la délinquance acquisitive, mais également du côté des hommes, les femmes étant bien moins nombreuses devant les instances. Derrière ce portrait type se cachent en fait des profils différents qui s'articulent bien avec la variété des situations. Spécialiste du vol au Moyen Âge, V. Toureille souligne, par exemple, qu'« il n'y a pas d'heure pour voler, pas de lieu non plus, ni de saison et si tout le monde ne vole pas, en revanche, tout se vole!». Pour punir ces actes, la justice médiévale mobilise un droit criminel qui a la particularité de 
ne pas être homogène. Il existe, en effet, une diversité des droits qui renvoie à la multiplicité des tribunaux et des jugements. Cet état de fait n'empêche pas la procédure suivie devant les instances d'être élaborée et respectueuse des droits des plaideurs. Le juge médiéval est tenu de s'appuyer sur des preuves légales, son intime conviction n'étant pas suffisante. Quant à l'idéal de la justice, il consiste à concilier réparation et punition, sachant que, lorsque des peines sont prononcées, celles-ci ne suivent pas obligatoirement ce que la norme prescrit, tout comme la peine prescrite peut ellemême être différente de la peine exécutée. La punition du crime s'inscrit alors entre le désir de frapper fort les esprits par l'exemplarité de certains châtiments et le pardon. L'auteure explique bien que la justice criminelle médiévale ne peut pas s'envisager du seul point de vue de la répression ou de la peine de mort car le roi - et certains princes -, qui détient le pouvoir de châtier, possède également celui de gracier les criminels via l'octroi de lettres de rémission ou de grâce.

Outre le fait de répondre aux questions posées en introduction et tout au long de l'ouvrage, la conclusion rappelle qu'il est possible de faire des parallèles intéressants avec la société telle qu'elle se donne à voir aujourd'hui, tout en soulignant également les différences, parfois importantes, entre les sociétés médiévale et contemporaine. Comme l'indique l'auteure elle-même, "en voulant traiter du crime, on ne peut s'empêcher de penser au présent». Bousculant les poncifs sur le Moyen Âge, V. Toureille montre ainsi que la documentation dont dispose le médiéviste témoigne " d'une communauté qui s'interroge sur la nature des crimes, sur la preuve, sur le traitement des criminels et, déjà, sur celui de la récidive ", autant d'éléments attestant que la société médiévale est loin d'être archaïque. De même, l'auteure rappelle que «le millénaire médiéval fonda l'essentiel de nos institutions modernes ». Crime et châtiments au Moyen Âge est un ouvrage de synthèse très intéressant, bien organisé et riche sur le sujet; on ne peut qu'en recommander la lecture. 